\section{Access to special care dentistry, part 3. Consent and capacity}

\author{
A. Dougall ${ }^{1}$ and J. Fiske²
}

VERIFIABLE CPD PAPER
IN BRIEF

- The Mental Capacity Act 2005 sets out a legal framework on how to act where an adult is not considered to be competent to give informed consent.

- Some conditions impact on the consent process and may lead to invalid consent if adjustments are not made to the way in which information is given and obtained.

- Physical intervention may rarely be required in the dental setting and must be carried out within a legal and ethical framework.

This article considers what is meant by informed consent and the implications of the Mental Capacity Act in obtaining consent from vulnerable adults. It explores a number of conditions which impact on this task, namely dyslexia, literacy problems and learning disability. The focus on encouraging and facilitating autonomy and the use of the appropriate level of language in the consent giving process ensures that consent is valid. The use of appropriate methods to facilitate communication with individuals in order to be able to assess capacity and ensure that any treatment options that are chosen on their behalf are in their best interests are outlined. The use of physical intervention in special care dentistry in order to provide dental care safely for both the patient and the dental team is also considered.

This article will consider what is meant by informed consent and the implications of the Mental Capacity Act in obtaining consent. It will also explore the impact of a number of conditions on

\begin{tabular}{l} 
ACCESS TO SPECIAL \\
CARE DENTISTRY \\
\hline 1. Access \\
2. Communication \\
3. Consent \\
4. Education \\
5. Safety \\
6. Special care dentistry services for \\
adolescents and young adults \\
7. Special care dentistry services for \\
middle-aged people. Part 1 \\
8. Special care dentistry services for \\
middle-aged people. Part 2 \\
9. Special care dentistry services for \\
older people
\end{tabular}

\footnotetext{
'Lecturer and Consultant for Medically Compromised Patients, Division One/Special Care Dentistry, Dublin Dental School and Hospital, Lincoln Place, Dublin 2, Ireland $:{ }^{2^{*}}$ Chairperson of the Specialist Advisory Group in Special Care Dentistry/Senior Lecturer and Consultant in Special Care Dentistry, Department of Sedation and Special Care Dentistry, King's College London Dental Institute, Floor 26, Guy's Tower, London, SE1 9RT ${ }^{*}$ Correspondence to: Dr Janice Fiske Email: Janice.Fiske@gstt.nhs.uk
}

achieving consent, namely literacy, dyslexia and learning disability. It will focus on encouraging and facilitating autonomy in the consent giving process.

\section{INFORMED CONSENT}

Informed consent is required from all patients or, in the case of children, parents. Without it, dental treatment technically and legally becomes assault. The model of informed consent comes from medical practice and is based on freewill, capacity and knowledge. Such knowledge needs to be sufficient for the person to come to a decision to refuse or agree to the proposed treatment. Hence, the patient, or parent/guardian, must understand the potential risks and benefits of the treatment and legally agree to accept those risks in writing. Furthermore, the risks and possible side effects must be explained in easy to understand language, so that consent means that the consenting person understands what they are agreeing to and feels under no pressure to give a particular response. ${ }^{1}$

Giving consent to a procedure does not necessarily waive the patient's legal rights. The healthcare professional still has to follow through using the proper standard of care as the patient can still make a claim if the health provider functions incompetently. Informed consent can be complex to evaluate, because neither expressions of consent, nor expressions of understanding of implications, necessarily mean that full adult consent was in fact given, or that full comprehension of relevant issues has been internally digested. ${ }^{1}$ Many times, consent is implied within the usual subtleties of communication, rather than being explicitly negotiated verbally or in writing. Consequently, there is always a degree to which informed consent must be assumed or inferred, based upon observation, knowledge, or legal reliance. In medical or formal circumstances, explicit agreement by means of signature, which may usually be relied upon legally, is the norm. In the dental setting, implied consent is assumed if a patient sits in the dental chair and voluntarily opens their mouth for dental examination or treatment. It is prudent to obtain written consent for irreversible procedures, such as exodontia, and it is a requirement to obtain it for procedures being carried out with sedation or general anaesthesia. For many other procedures, implied and verbal consents are normal practice.

Essentially, informed consent: ${ }^{2}$

- Provides the patient with information about the procedure, including the risks, benefits and alternatives; also its nature and purpose 
- Ensures that the patient understands the information given, for example by providing information sheets written in the subject's language

- Ensures that the decision is made by the patient and that agreement to the procedure is voluntary, eg by requiring written consent and, where subjects are not competent to agree, obtaining consent by proxy eg from a guardian or advocate

- Includes an obligation to respect the patient's decision, even where the clinician considers the decision not to be in the patient's best interests.

Competent adult patients have the legal right to withhold their consent to treatment, or to withdraw it at any point during treatment. This rule applies to all areas of treatment and care, even where treatment offered is for a serious or severe condition. Where a person cannot be considered competent, another set of legal principles are effected, by the common law and now by statute of the Mental Capacity Act 2005. ${ }^{3}$

\section{THE MENTAL CAPACITY ACT $2005^{4}$}

The ability to give informed consent is governed by a general requirement of competency. In common law jurisdictions, adults are presumed competent to consent. This became a statutory requirement in 2007 when the Mental Capacity Act 2005 (MCA) for England and Wales came fully into force. The law in Scotland meets the needs of adults with incapacity through the Adults with Incapacity (Scotland) Act 2000. ${ }^{5}$

The MCA sets out a legal framework of how to act and make decisions on behalf of people who lack capacity to make specific decisions themselves. It sets out the core principles and methods for making those decisions and carrying out actions in relation to personal welfare, healthcare and financial matters. Its purpose is to assist and support people who may lack capacity, and to discourage anyone who is involved in caring for them from being overly restrictive or controlling. In essence, it aims to balance an individual's right to make decisions for themselves with their right to be protected from harm. The MCA achieves this by provision of a statutory legal framework empowering and protecting people who lack capacity to make their own decisions. This is underpinned by a decision-specific test for assessing mental capacity and clarification of the law in respect of how decisions are made and how care and treatment are provided on behalf of individuals who lack mental capacity. The MCA has five statutory principles: a presumption of capacity; provision of support to make decisions; the right to make unwise decisions; the requirement to act in the individual's best interests; and a requisite to consider the least restrictive intervention. ${ }^{6}$

In Scotland, the Adult with Incapacity (Scotland) Act 2000 requires that, if a dentist is of the opinion that an individual lacks capacity to consent to treatment, the authority to treat must be obtained, in most cases, from the medical practitioner primarily responsible for their care. ${ }^{5}$

\section{Who does the MCA affect?}

The MCA affects people over 16 years of age with mental illness, dementia, learning disabilities, brain damage, confusion, drowsiness, loss of consciousness, delirium, or concussion. It also includes those who lack capacity because of alcohol or drug use. The Act applies to everyone involved in the care of any individual who lacks the capacity to make their own decisions and, therefore, includes anyone acting in a professional capacity or role, such as healthcare professionals, social workers and care assistants. Emmett ${ }^{7}$ advises that any dentist who provides treatment for patients with mental incapacity due to any of the above conditions needs to be familiar with the Act and its accompanying Code of Practice, which sets out how the Act works on a daily basis.

\section{Capacity and lack of capacity}

Within the MCA, mental capacity is considered to be the ability to make a decision. Inherent in this definition is the ability to carry out the processes involved in decision making. This is considered to be more important than the decision itself. Whatever the circumstances, the starting point must always assume that a person has the capacity to make a specific decision. ${ }^{8}$
For the purposes of the MCA, 'a person lacks capacity in relation to a specific matter if at the material time (s)he is unable to make a decision for her/himself in relation to the matter, because of an impairment of, or a disturbance in, the functioning of the mind or brain'. ${ }^{4} \mathrm{~A}$ person is considered to lack capacity if they have an impairment or disturbance affecting the way their mind or brain works and the impairment or disturbance means that they are unable to make a specific decision at the time it needs to be made. The impairment or disturbance does not have to be permanent and a person can be considered to lack capacity if the loss of capacity is partial, temporary, or varies over time. Also, a person may lack capacity to make a decision about one issue but not others, depending on the complexity and the implications of the decision. ${ }^{8}$

\section{Assessing capacity}

Any health professional considering an individual to lack capacity is required to provide proof by showing that, on the balance of probabilities, the individual lacks capacity to make a particular decision at the time it needs to be made.

The Act sets out a two-stage test of capacity. The first question, or 'threshold test', asks 'Is there an impairment of, or disturbance in, the functioning of the person's mind or brain?' If the answer to this is yes, the next question, or 'functional part of test' asks 'Is the impairment or disturbance sufficient such that the person lacks the capacity to make that particular decision?' A person is considered unable to make a decision if they cannot:

- Understand information relevant to the decision to be made

- Retain that information in their mind

- Use or weigh up that information, or

- Communicate their decision.

However, this consideration must be made in the light of the questions set out in Table $1 .{ }^{4,9}$

\section{Best interests}

If having followed all of the above stages, the person is considered to lack capacity, a decision can be made on their behalf. The MCA states that such a 
Table 1 Questions to be asked when assessing capacity

- Does the person have all the relevant information they need to make a decision?

- If they have a choice, have they been given information on all the alternatives?

- Could information be presented in a way that is easier for them to understand, eg by using simple language or visual aids?

- Have different methods of communication been explored if required, including non-verbal communication?

- Could anyone help with communication, eg a family member, carer or interpreter?

- Are there particular times of day when the person's understanding is better?

- Are there particular locations where they may feel more at ease?

- Could the decision be put off to see whether the person can make the decision when circumstances are right for them?

Table 2 People whose views need to be taken into account when considering best interests

- Anyone the person has previously named as someone they want to be consulted

- Anyone involved in caring for the person, other than paid carers

- Anyone with an interest in the person's welfare

- An attorney appointed under the Lasting Power of Attorney clause of the MCA 2005

- A deputy appointed by the Court of Protection

decision 'must be done, or made in her/ his best interests' and it applies to everyone making decisions on that person's behalf, in relation to all aspects of financial, personal welfare and healthcare decision-making and actions.

Working out what is in someone's best interests cannot be based simply on age, appearance, condition or behaviour and all relevant circumstances must be considered. Additionally, every effort should be made to encourage and enable the person who lacks capacity to take part in the decision-making process.

The MCA best interests checklist requires that:

1. People are treated as individuals

2. The questions set out in Table 1 have been answered

3. The decision-maker has considered, as far as they are 'reasonably ascertainable', the person's past and present wishes and feelings and in particular, any relevant written statements made when they had capacity; the beliefs and values that would be likely to influence their decision if they had capacity; and the other factors that they would be likely to consider if they were able to do so
4. The decision-maker has taken into account, where appropriate, the views of the people set out in Table 2 and must show they have thought carefully about whom to consult

5. The views of the people consulted by the decision maker are taken into account.

It is essential that accurate and full records are made of the stages followed to reach a decision as to whether a person has capacity or not, what that decision was and why it was reached.

The MCA introduces a new criminal offence of ill-treatment or willful neglect of people who lack capacity. Within the law, 'helping with personal hygiene' (which includes oral hygiene) will attract protection from liability so long as the individual has complied with the MCA by assessing a person's capacity and acting in their best interests. ${ }^{10}$

\section{Other provisions of the MCA}

Decision making will be allowed without any formal procedure unless specific provisions apply, such as a written advance decision, lasting powers of attorney or a decision by the court of protection. ${ }^{11}$
However, the MCA allows for people to put arrangements in place, while they have the capacity to make decisions, that will be acted upon as required when or if they have lost capacity. These are:

1. Advance decisions - the Act permits people 18 years of age and over to make advance decisions, while still capable, to refuse 'specified medical treatment' for a time in the future, when they might lack the capacity to consent or refuse. Provided an advance decision is valid and applicable to current circumstances, it has the same effect as a decision that is made by a person with capacity and must be followed

2. Lasting power of attorney (LPA) - the LPA allows adults aged 18 and over who have capacity, to appoint attorneys to make decisions about their personal welfare, including healthcare and medical treatment decisions, and their property and affairs.

Additionally, the Act allows for 'Court appointed deputies' (CADs), who can act for and make decisions on behalf of individuals whose condition makes it likely that they will lack capacity to make decisions in the future. The CAD must follow the Act's statutory principles, act in the person's best interests, have regard to the guidance in the Code, and only make decisions authorised by the Court. This element of the Act is likely to be used for people with learning disability and it is likely that the Court of Protection will appoint family members as the deputy or deputies.

\section{Independent mental capacity advocates (IMCAs)}

Where a person who lacks capacity does not have anyone who can act on their behalf or support them, the IMCA fulfils that role. IMCAs must be independent and should be instructed and then consulted for people lacking capacity who have no-one else to support them, whenever an NHS body or local authority is proposing serious medical treatment or to arrange/change accommodation in hospital or a care home. IMCAs would not normally be involved in the provision of routine dental care but may well 
be involved in decisions about treatment options for oral cancer. All primary care trusts (PCTs) should have someone in place who can answer questions relating to the MCA and advise regarding the use of IMCAs.

Essentially the MCA and the Adult with Incapacity (Scotland) Act 2000 govern decision making on behalf of adults, where they lose mental capacity at some point in their lives, or where the incapacitating condition has been present since birth. They do so through the provision of statutory and new powers to safeguard people who lack mental capacity; empowering people to make decisions for themselves where possible; and placing individuals at the heart of the decision-making process. ${ }^{12}$

\section{ENSURING VALID CONSENT}

A number of factors can affect a person's ability to provide consent, even when they have the capacity to do so. There are also circumstances where, unless correct measures are taken, capacity cannot be properly assessed and may not, therefore, be evident. Literacy, dyslexia and learning disability will be considered in this context.

\section{Literacy}

The ability to read is a prerequisite to understanding information provided in written format. Literacy, which is defined as the "use of printed and written information enough to function in society', may not be as high as we imagine. ${ }^{13}$ The 1992 US National Literacy Survey found that a fifth of adult Americans were functionally illiterate, reading at or below the level of a 10-year-old child, and would have difficulty in understanding healthcare information, including consent forms. ${ }^{13}$ Another quarter was only marginally literate. Whilst there are currently no similar surveys in the UK, it is known that around seven million people in the UK have literacy, numeracy and language skill needs. ${ }^{14}$ There is still a stigma attached to poor literacy and people may prefer not to disclose this information. There is even an example of a person pretending to have a visual impairment (a disability which results in sympathy and offers of help) rather than disclosing a literacy problem. However, lack of disclosure prevents people being offered the help and support that they need. ${ }^{15}$

As the impact that health literacy can have on health is realised, it is climbing the healthcare agenda. The Kirsch study $^{13}$ in 1999 found:

- 33\% of English-speaking hospital patients could not read or understand basic health materials

- $42 \%$ could not understand instructions to take medication on an empty stomach

- 25\% did not understand information on an appointment slip, and

- 60\% did not understand a standard consent form.

Health literacy relates to how well someone can read or comprehend health information (delivered in written, oral or visual format) and then act on this information. ${ }^{14}$ It has cultural, language and educational components. Low health literacy can seriously limit a patient's ability to prevent or manage disease. ${ }^{16}$ For example, people with low health literacy are more likely to make medication or treatment errors, become hospitalised ${ }^{17}$ and have problems negotiating healthcare systems. Older people and those in poor overall health have the worst health literacy. Research in this area suggests that patients retain as little as $12 \%$ of explanations, creating significant health risks, ${ }^{13,15}$ and this highlights the gap between what patients actually understand and what healthcare professionals expect them to know.

When developing written oral health information material, it is appropriate to consider the reading ability of the group(s) it is aimed at and tailor the information to suit the literacy skills of patients and carers in that group. ${ }^{18}$ The challenge is to meet the patient's literacy needs and, whilst not stigmatising the low literacy groups, avoid the over-simplification that can turn off more literate people's attention. Standardised measurements can be used to assess readability, the Flesch Reading Ease Score being one of the most validated and widely used. This score, ${ }^{19}$ which is endorsed by the British Dyslexia Society, rates text on a 100-point scale such that the higher the score, the easier it is to understand the document. For most standard documents, the aim is for a score of approximately 70 to 80 . According to the Flesch score, British consent forms have been assessed as requiring a college level of literacy to understand the document. ${ }^{19}$ Hence, as the reading age of the UK population averages somewhere around 13-14 years, many patients will not understand consent forms. ${ }^{20}$

Microsoft Word provides a facility in the tools menu which makes checking readability straightforward. When it finishes checking spelling and grammar, it can display information about the reading level of the document based on the average number of syllables per word and words per sentence.

\section{Language}

In considering language it is important to bear in mind both fluency and literacy. Some ethnic groups, or members of ethnic groups, will be fluent in English whilst others will not, and there may be a gender bias. For example, according to the Fourth National Survey of Ethnic Minorities, English was spoken by $75 \%$ of Bangladeshi men but only $4 \%$ of women aged 45 to 64 years. ${ }^{21}$ Although English language skills improve in the younger generations, only around 30\% of Bangladeshi women in the 25-44 year age group were fluent in English, compared with nearly $80 \%$ in 16-24 year old women. ${ }^{21}$ Where fluency is poor, interpreter services may be required to establish understanding and facilitate gaining consent. Good fluency does not necessarily extend to good literacy, and a person who is able to communicate well in a language may not be able to read that language well enough to understand information leaflets or consent forms. Literacy levels in some ethnic groups are low, for example, a level as low as $16 \%$ has been reported in the Bangladeshi community. ${ }^{22}$ Where there is good literacy, the individual should be provided with information sheets in their language of choice. Where there is poor literacy, it may be necessary to rely on interpreter services.

In a recent study of young Bangladeshi adults with a learning disability, 88.5\% spoke English and chose to do the survey in English. ${ }^{23}$ Despite this situation, one of the study participants who spoke 
Table 3 Strategies for communicating and providing informed consent for people with dyslexia or other literacy problems

- Communicate slowly and clearly in a quiet location with minimal interruption

- Give instruction or introduce concepts one at a time

- Highlight the salient points in a document and give summaries of key points

- Write down the important points and provide information on coloured paper. Find out which colour helps the person best

- Encourage the person to take notes and check them back as this helps them to remember

- Examine and discuss other ways of giving the same information to avoid use of written media

- Utilise information prepared in other formats such as audio or videotape

- Organise details on paper using diagrams and flowcharts

- Give verbal rather than written instruction using a digital or tape recorder

- Ask for the instructions to be repeated back, to confirm that the instruction has been understood correctly, and document using a digital recorder if necessary

English commented that: '[I have] never been to the dentist, [I would] like to go, but need someone to come with me... and I would [go if] someone make me appointments, as my parents don't speak English. So I can't go.' Somewhat paradoxically, his parents lack of fluency in English impacted on his dental attendance.

\section{Dyslexia}

Dyslexia is a common condition, affecting one in ten of the population, that can impact on understanding. Following the Paterson ruling in 2007, it is recognised as a disability at all levels of the condition. ${ }^{24}$ This specific learning difficulty is characterised by difficulties in processing word-sounds and by weakness in short-term verbal memory. ${ }^{25}$ It is not related to intelligence, race or social background, and may affect up to $10 \%$ of your patients and your staff. ${ }^{26}$ These difficulties arise from inefficiencies in the language processing areas of the left hemisphere of the brain and appear to be linked to genetic differences. ${ }^{27}$ Dyslexia varies in severity and often occurs along with, and is complicated by, other specific learning difficulties such as attention deficit disorder and dyspraxia, which will be covered in the next paper in the series. There is evidence that many people with dyslexia have strengths and abilities in tasks that involve creative and visual based thinking. ${ }^{26}$

People with dyslexia and literacy problems will remember as little as $10 \%$ of what they read and as little as 50\% of what they hear. However, it is important to realise that they remember $90 \%$ of what they say as they do something, ${ }^{26}$ thus questioning the suitability of the standard consent form for this group. ${ }^{19}$ Table 3 provides guidelines for communicating and providing informed consent for people with dyslexia or other literacy problems.

Dyslexia is usually a "hidden disability' and often older and middle-aged individuals are themselves unaware that they have such difficulties. ${ }^{28}$ Indeed, in a recent article looking at dyslexia in undergraduate and postgraduate dental students, 8\% identified themselves as dyslexic, whilst psychometric testing identified 33\% of the group as having scores suggesting the presence of dyslexia. ${ }^{29}$ Dyslexia is not the same as a problem with reading, and many people learn to read but continue to have difficulties with spelling, writing, memory and organisation. It often causes problems in arithmetic and recalling number related facts. The degree to which dyslexia causes problems in learning and everyday life depends on many factors, including its severity, the other strengths and abilities the person has and the kind of teaching and support that they have been given. For example, printing information on coloured paper makes it easier to read for some people with dyslexia. The colour depends on the individual, but black print on cream paper is

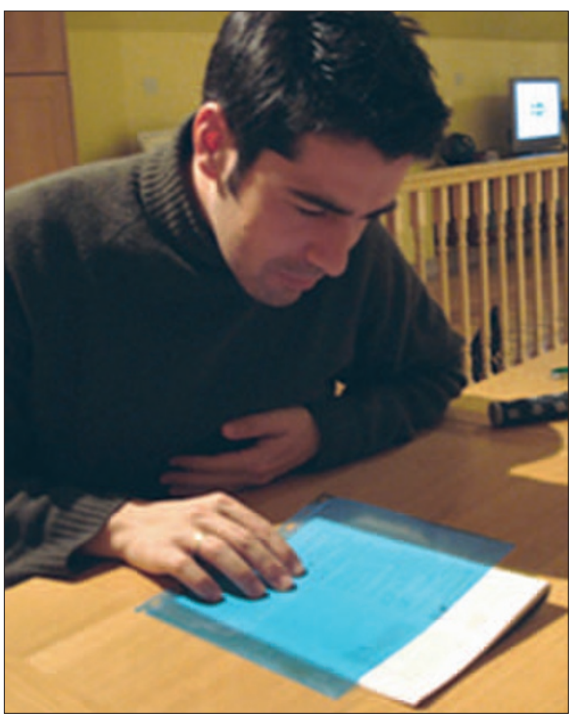

Fig. 1 Coloured acetate overlay being used to facilitate reading by a person with dyslexia

the combination that suits most people. Some people use a coloured acetate overlay to achieve the same effect (Fig. 1). ${ }^{26}$ Research shows that early intervention is effective ${ }^{30}$ and the key to success is through improving skills and developing positive compensatory and coping strategies. $^{31}$

Any changes you make to accommodate people with dyslexia are good practice for everyone. When providing written information, bear in mind that font size and form are important. Fonts should be rounded to allow for space between the letters, with Arial and Trebuchet MS being preferred to Times New Roman. The latter contains confusing ticks and tails which can create difficulties. In line with RNIB guidelines for visually impaired people, it is recommended that font size 14 is used on matt paper, to prevent glare. ${ }^{32}$

\section{Learning disability}

Learning disability is a significant impairment of intelligence and social functioning acquired before adulthood. ${ }^{33}$ Its cause can be genetic, congenital or acquired. ${ }^{34}$ People with learning disability, to varying degrees, have difficulties understanding, learning and remembering new things, and in generalising learning to new situations. These difficulties with learning may lead to difficulties with social tasks, such as communication, self-care, awareness of health, and safety. ${ }^{35}$ They may also impact on 
capacity, the ability to make decisions and the ability to give informed consent. People with severe learning disability, where a lack of capacity is more apt to be clear cut, are likely to receive their dental care in the secondary care sector. People with mild to moderate learning disability are more likely to receive their care in the primary dental care services - either general dental practice or salaried services. This group will need to have their capacity assessed before invasive or irreversible dental procedures are carried out. Implied or verbal consent will suffice for examinations and minimally invasive procedures where the individual is co-operative.

There are no reliable statistics regarding the number of people with learning disabilities in the UK. Estimates suggest that there are between 230,000 and 350,000 people with severe learning disability and 580,000 to 1,750,000 with mild to moderate learning disability in the UK, ${ }^{35}$ and more than 29,000 people with a severe or profound learning disability live at home with a carer aged over $70 .^{36}$ The commonest genetic causes of learning disability are Down's syndrome and Fragile $\mathrm{X}$ syndrome, with an incidence of around 1 in 700 and 1 in 4000 births respectively. ${ }^{33}$ Learning disability is common and every dental team will meet affected patients.

Mencap states that "there are many different types of learning disability and they can be mild, moderate or severe'. ${ }^{33}$ It also refers to people with 'profound and multiple learning disabilities' (PMLD), that is, people with more than one disability, the most significant of which is a profound learning disability. The additional disabilities may be sensory or physical, complex health needs or mental health difficulties. People with PMLD usually have great difficulty communicating, may have behaviours that challenge us, and need high levels of support with most aspects of daily life.

Additional disabilities commonly occur alongside learning disability, such as epilepsy or physical disability, without the individual being considered to have PMLD. There are also some conditions that are more commonly associated with learning disability, but not everyone who has the associated condition has

\section{Table 4 A staged approach to informed consent}

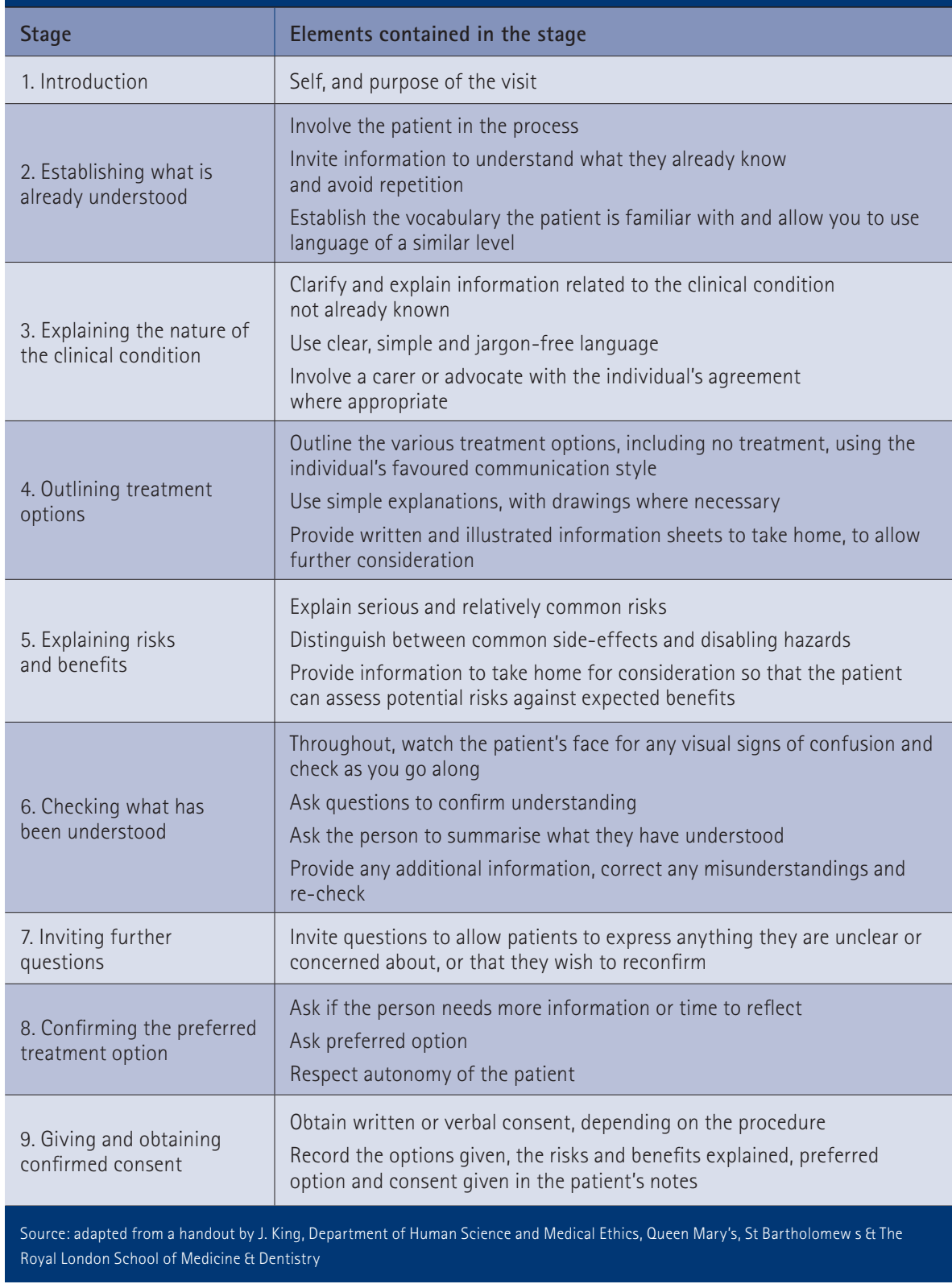

a learning disability. Examples include cerebral palsy, epilepsy (the incidence of which rises to $10 \%$ in adults with Down's syndrome and is 30\% overall in the learning disability population), autism (which occurs in approximately one third of people with Fragile X syndrome) and Asperger's syndrome.

The degree of learning disability impacts on how much a person can learn, and their ability to make decisions and to participate in daily living activities. Some people with a mild learning disability do not need much support in their lives, whilst others may need support with many activities - from getting dressed and going shopping to filling out forms. A learning disability does not preclude someone from learning provided they get the right support. The Government White Paper Valuing people: a new strategy for learning disability for the 21st century states that people with learning disabilities should have independence, choice, rights and inclusion. ${ }^{36}$ This is not the same as assuming that everyone with a learning disability has the capacity to make decisions. Some people with learning disability will have capacity, whilst others will not. Thus, it is always prudent to ask who, if anyone, has been appointed as their CAD. The situation is not always clear cut: some people will have fluctuating capacity (which is why capacity needs to be assessed on every 
occasion) and others will have a degree of capacity depending on the complexity of the decisions to be taken and the associated implications as a result of the decision. For example, an individual with toothache may understand that removal of the tooth means the pain will stop and would, therefore, opt to have the tooth extracted. They may not understand that in removing this tooth it is lost forever and may impact on appearance, self-esteem, eating, etc. Neither may they realise the complexity of having the tooth replaced. If they were helped to understand the implications, they may very well opt to have the tooth restored. A staged approach to informed consent, outlined in Table 4, can be helpful.

\section{Use of health services}

Generally speaking, people with a learning disability use services less than the general population and, when they are used, the healthcare outcomes are also fewer. However, it is worth noting the Government's drive to establish autonomy and removal of inequalities in healthcare access and outcomes for people with a learning disability, as this will impact on what the primary care dental team is expected to do to in the provision of care for this group of people. ${ }^{36-39}$ They will be expected to do whatever is possible to communicate in such a way that the individual is:

- Provided with the opportunity of independence and autonomy, whereby they are empowered to make their own decisions

- Offered choice through a range of options and has that choice respected, and

- Communicated with in such a way that $\mathrm{s} /$ he is able to assert her/his rights through choice, including the right to say no.

Additionally, they will be expected to provide their service in a way that invites inclusion, for example using alternative means of communication. Without incorporating all these factors into daily practice it is not possible to assess the individual's capacity to make decisions, nor to comply with the MCA.

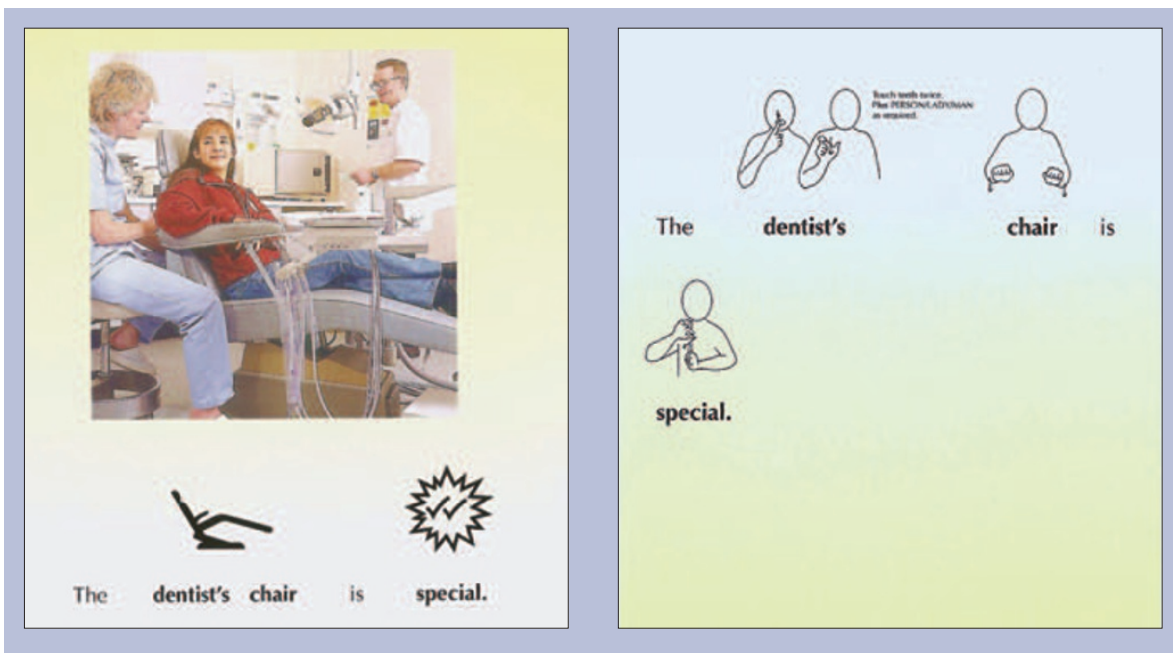

Figs 2a and $2 \mathrm{~b}$ A double-page spread from Going to the dentist $t^{44}$ showing how Makaton utilises pictures, symbols, signs and words

\section{Communication and learning disability}

Effective communication is fundamental to achieving the principles of independence, choice, rights and inclusion. Organisations (including healthcare providers) working with people who have learning disabilities are expected to develop communication policies and to produce and disseminate information in accessible formats. ${ }^{36}$ This is challenging, as people with learning disabilities do not have a single set of language tools due to their dependency on speech and language therapists to provide them with an individually tailored communication plan. People with PMLD may require individual communication techniques and effective use of new technology, ${ }^{36}$ or they may be unable to use any of the recognised means of communication and be dependent on others to interpret their needs and choices through observation of their communicative behaviour. ${ }^{40}$ Whilst the role of family and carers can be important in effective communication with some people with learning disability, it is important to treat the individual with dignity and address them directly throughout the communication process. However, never 'ASSUME' that someone is unable to communicate, as it will only make an 'ASS' out of 'U' and 'ME'. ${ }^{41}$ Mencap produces Make it clear, a guide to making information easy to read and understand. It is very useful when producing patient information for people with learning disabilities. ${ }^{42}$

\section{Commonly used methods of communication}

Commonly used techniques for learning and communication for people with mild and moderate learning disabilities include 'Makaton' and 'Signalong', which both use signing and symbols; 'Widgit software', which uses symbols for writing; and 'Talking Mats', which uses pictures and symbols.

\section{Makaton}

Makaton is used by children and adults with a broad range of communication needs, often associated with learning difficulties, from those at a very early stage of communication awareness and development to others more able. Users include people with communication needs arising from learning disability, severe physical disability, autistic spectrum disorders and specific language disabilities. Makaton is a system of symbols and signs used with speech, the written word, or on their own to provide a visual representation of language which increases understanding and makes expressive communication easier. ${ }^{43}$

Its multi-modal approach, where one mode facilitates another, has been shown to increase personal expression and development, participation in interaction and socialisation and to increase access to education, training and public information. ${ }^{43}$ Makaton has a "core vocabulary', which provides a common foundation for most users, and a 'resource vocabulary', which provides a 
large topic-based resource of additional signs and symbols that can be added as necessary to the core vocabulary. An important feature is that it provides vocabulary for the person with communication needs and for the family, carers and professionals. An excellent resource for the dental team is a book in Makaton called Going to the dentist..$^{44}$ It provides a page by page, stage by stage visit to the dentist set out in photographs, symbols, signs and words which can be used for 'written' or ‘spoken' communication (Fig. 2). It covers common dental procedures such as examination, radiography, local anaesthesia, fillings and tooth extraction as well as general anaesthesia. It can be used in the surgery or pages can be photocopied for home use as part of the preparation for the visit.

Makaton symbols and signs can be used at three different levels. The most basic level is where one symbol/sign represents a whole sentence or message; the next where key symbols/signs are used to convey all the meaning, but not the grammatical items; and the most sophisticated level is where Makaton symbols and signs are used for every word and linguistic element in the sentence. To increase user access, The Makaton Charity provides translation services into Makaton symbols and signs for public information, inhouse guidelines, individual programme plans, documents, leaflets, etc. ${ }^{45}$ Training is also available through The Makaton Charity's symbol and sign enhancement courses for professionals and carers to develop these particular skills. ${ }^{45}$

\section{Signalong}

Signalong is a sign-supporting system based on British Sign Language, designed to help children and adults with communication difficulties, mostly associated with learning disabilities. This system requires you to speak as you sign and is not intended to replace speech. It is a total communication system in which every clue to meaning is given by using body language, facial expression and voice tone to reinforce the signed and spoken message. The Signalong Group publishes manuals and other visual communication resources, provides a full training service and will research signs which are not yet published. ${ }^{46}$

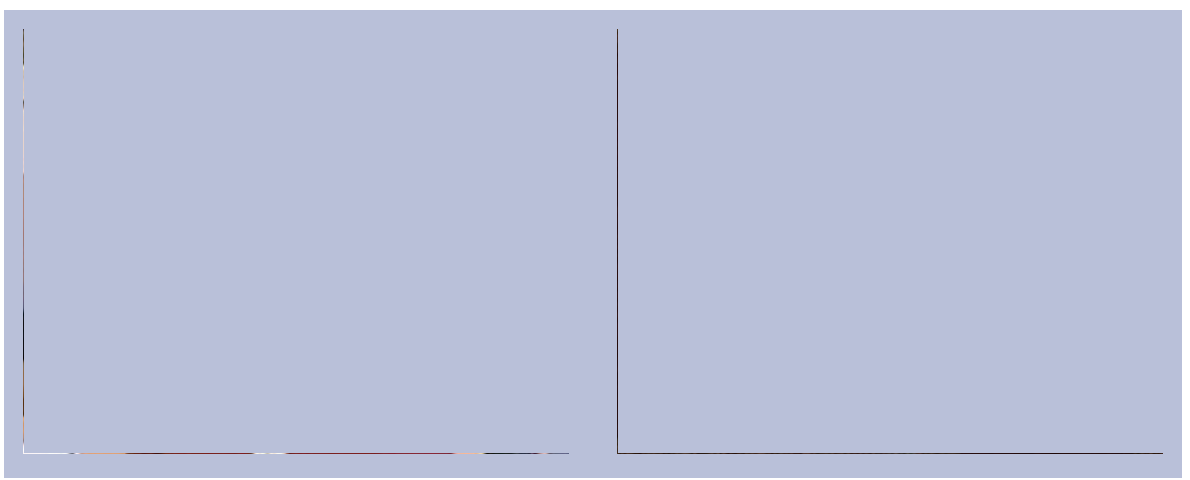

Figs 3a and 3b A healthcare professional and client using the 'Talking Mats' system to facilitate the client's expression of views and feelings

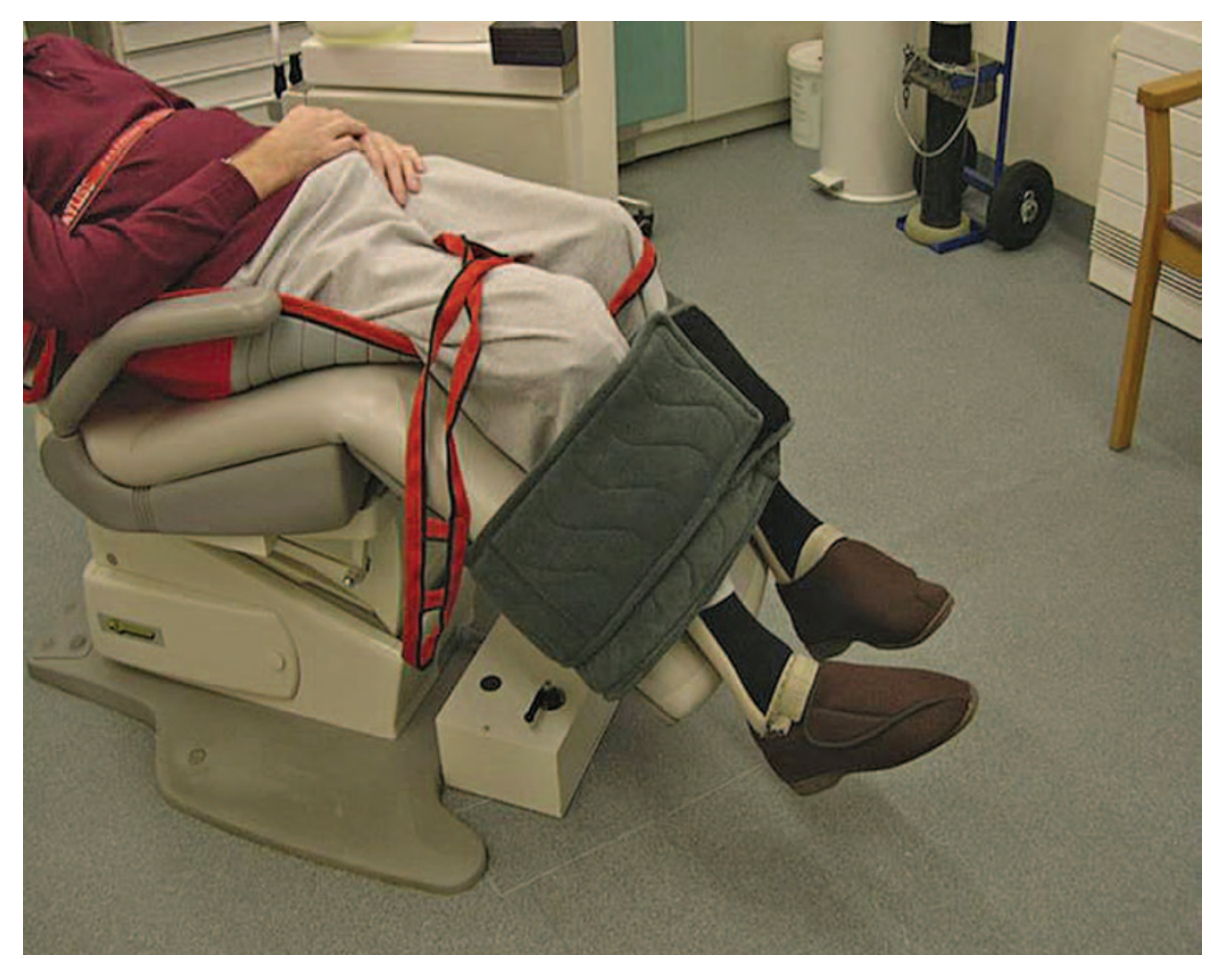

Fig. 4 Large Velcro straps used to control ataxic or jerky leg movements which could endanger the patient or staff

\section{Widgit software}

Widgit Software design and supply computer software packages which are designed to help develop literacy in adults with learning disabilities and children with special needs through the use of pictures, symbols and words. ${ }^{47}$

\section{Talking Mats}

Talking Mats is an established communication tool, which uses a mat with pictures and symbols attached as the basis for communication. It is designed to help people with communication difficulties to think about issues discussed with them and provide them with a way to effectively express their opinions. ${ }^{48}$ Talking Mats can help people arrive at a decision by providing a structure where information is presented in small chunks, supported by symbols, giving people time and space to think about information, work out what it means and say what they feel in a visual way that can be easily recorded. Research has shown that this interactive resource improves both the quality and quantity of information gained through its use of three sets of picture symbols. ${ }^{49}$

The picture sets cover 'topics' - whatever you want to talk about; 'options' - relating specifically to each topic; and 'visual scale' - which allows participants to indicate their general feelings about each topic and option, eg happy, unsure, unhappy (Fig. 3). Both video and digital cameras can also be used, the former to ensure non-verbal 
communication is taken into account and the latter to give a permanent record of the mat. This system provides an excellent method of assessing if an individual with a learning disability understands an issue sufficiently to have capacity to give consent. There are a number of Talking Mats packages available and symbols for dentistry were reported as being in development in 2007.49

\section{GENERAL GUIDELINES FOR PHYSICAL INTERVENTION}

A lack of effective communication can lead to frustration, which in turn can lead to withdrawal or anger and aggression expressed against self or others. This is seen as 'challenging behaviour'. The British Institute of Learning Disability (BILD) uses the term challenging behaviour to emphasise that the behaviour is a challenge to us and the situation or circumstances a person finds himself or herself in..$^{50}$ BILD considers it to be an individual's way of saying 'I don't like [or want] this', and 'I want to change [or stop] it'. They state that there are always good reasons for the challenge. For example, people with learning disabilities who have communication difficulties can find it difficult to challenge things verbally (possibly because they do not have the confidence to challenge people they see as 'authority figures') and so challenge physically. People with PMLD may be unable to remove themselves from a situation they dislike, or may be unable to make themselves understood, and so respond behaviourally.

Challenging behaviour is common in people with learning disability, estimates suggesting about $20 \%$ of children and $15 \%$ of adults exhibit some form of challenging behaviour. ${ }^{51}$ Whilst there is currently no systematically recorded evidence of the extent to which physical interventions are used in services for people with learning disability and/ or autism, research has suggested that $50 \%$ of people with intellectual disabilities and challenging behaviour will have physical interventions used on them at some point in their lives. ${ }^{50}$ The behavioural challenges presented by a small number of adults and children with learning disabilities, autism, or emotional and behavioural difficulties mean that the use of some form of physical intervention may be unavoidable. It may be required occasionally in the dental setting in order to be able to provide care safely for both the patient and the dental team. Where it is used, there is a need to ensure that such interventions are carried out within a legal and ethical framework that sets out explicit safeguards for the person with a learning disability and for staff. ${ }^{52}$

\section{What is physical intervention?}

Where behaviour management strategies fail, to help a patient cope with dental treatment some form of intervention may be required. According to the British Society for Disability and Oral Health (BSDH) guidelines on physical intervention, oral, intravenous and inhalation sedation or general anaesthesia used as adjuncts to facilitate dental care must all be viewed as forms of clinical restraint. ${ }^{52}$ General anaesthesia (GA) is described as the ultimate physical intervention as the patient is rendered unconscious and is unable to withdraw consent at any time during treatment. The guidelines suggest that there are times when reasonable physical restraint is preferable to more extreme alternatives, such as GA, and might be acceptable for single short interventions. Even so, it asserts that this approach should only be taken after all other approaches have been considered. ${ }^{52}$

\section{Types of physical intervention}

BILD policy framework describes three broad categories of physical intervention, ${ }^{53}$ the third of which is unlikely to be used in the general dental setting:

1. Direct physical contact between a member of staff and a service user, eg holding a person's arms and legs to stop them attacking someone

2. Materials or equipment which restrict or prevent movement, eg placing splints on a person's limbs to restrict movement (Fig. 4)

3. The use of barriers, such as locked doors, to limit freedom of movement, eg placing door catches or bolts beyond the reach of service users.

The BSDH guidelines on physical intervention set out the following types

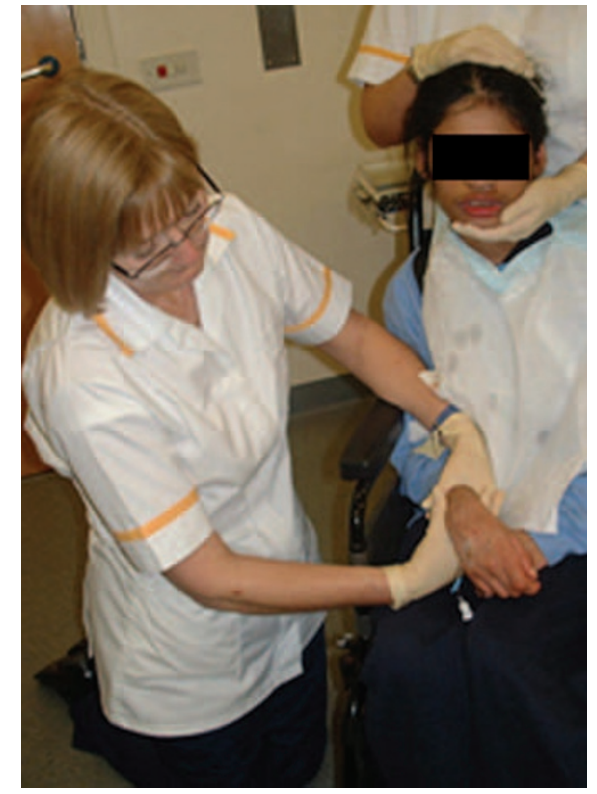

Fig. 5 Gentle head holding to contain and control sudden excessive movement during intra-venous cannulation

of intervention, which can be carried out by a member of the dental team, parent/carer or accompanying responsible person:

1. Forming an 'arc' over the patient's body which permits the individual to move but extensive movements are restricted by contact with the person's arcing arm

2. Gently holding part of the patient's body, with pressure only being applied in the form of resistance or drag in response to excessive movement (Fig. 5). Rather than immobilising the patient, the speed and force of their movement is contained

3. Using a blanket to swaddle the patient is only considered acceptable for urgent treatment, where a patient is likely to respond aggressively to any attempts to provide treatment. ${ }^{52}$

\section{When to use physical intervention}

The Department of Health guidance on the use of physical intervention sets out the circumstances in which it can be used..$^{52,53,54}$ Some key principles are that physical interventions should be used in the context of other strategies for the individual, after other less intrusive methods have been tried and found to be ineffective, and as a part of individual support plans. It should only be 
used if it is considered to be in the best interests of the individual. If it is not possible for the patient to be a part of the decision making process about oral care or where it is judged that they do not have the capacity to consent, the views of parents or carers should be taken into account. At all times, the emphasis must be on a proactive approach to care and not just managing aggressive or disruptive behaviour. ${ }^{52}$

The responsibility for physical intervention lies with the 'treating' dentist, irrespective of who undertakes the intervention. However, parents and carers have a role to play in both supporting any physical intervention and in expressing any concerns if they are uncomfortable with the procedure. ${ }^{52}$ Whilst physical intervention may deal with an incident of challenging behaviour and allow treatment to take place, it does not facilitate the individual with the disability learning to cope with the situation, so as to adopt a more appropriate behaviour in the future. Physical intervention should not be seen as a panacea and should be part of a strategy using additional techniques to help the person to learn how to adopt appropriate behaviour. Its use should also be subject to regular review.

\section{How to use physical interventions}

Service managers have a responsibility for the development of policies on the use of physical interventions and for ensuring that staff are appropriately trained. Staff training must make explicit reference to the values that underpin the use of physical interventions. Also, it needs to be regularly updated as where good strategies for prevention of challenging behaviour are used, it is likely that physical interventions will be used minimally and only occasionally. A code of practice for trainers in the use of physical intervention is available from BILD. ${ }^{55}$

Before any physical intervention, a risk benefit assessment should be undertaken that considers two areas:

1. The risk to the individual of not having the intervention and thus no oral care

2. The risk of the particular technique to be employed.
Any decision must be considered to be in the patient's best interests and the intervention must be considered to be reasonable and proportionate in the circumstances. ${ }^{52}$ An assessment of the patient must be undertaken prior to physical intervention to identify any contra-indications to the intervention, such as heart disease, breathing problems, recent fractures, or a history of dislocated joints. Additionally, intervention should be avoided in people with Down's syndrome, 20\% of whom may have atlanto-axial joint instability, where there is a small but real risk of acute or chronic neurological problems caused by this cervical spine instability. Although the risk is small, if a general anaesthetic is being used, care must be taken to avoid cervical injury whilst manipulating the head or neck in the unconscious person. ${ }^{56}$

It is mandated that physical intervention should be terminated if there are signs of extreme distress, breathing difficulties, seizures, vomiting, blue colouration of extremities (indicating restricted blood circulation), or mottling or blotchiness (indicating restricted blood circulation or bone fracture). It should be withdrawn slowly and in a measured way. ${ }^{52}$

Accurate records must be kept of any intervention to inform future episodes, to confirm appropriate procedures have been used to assess capacity and to confirm that an appropriate consent process was undertaken. The type of intervention used, the dental procedure carried out, who was consulted about the decision to use physical intervention, the outcome and future plans should all be recorded.

Professionals working with vulnerable people have a duty of care to treat them with dignity and to use all appropriate methods to facilitate communication so as to be able to assess capacity. This means treating people with respect and ensuring that any treatment options that are chosen on their behalf are in their best interests.

The authors wish to thank Homefirst Community Trust (Ballymena) for allowing them to reproduce two pages of their Makaton book Going to the dentist, used in Figures $2 a$ and $2 b$. They also wish to thank Joan Murphy, Research Speech and Language Therapist at the University of Stirling, for providing the illustrative material for Figures $3 a$ and $3 b$.
1. Action on Rights for Children. Informed consent webpage. http://www.arch-ed.org/issues/databases/informed_consent.htm (accessed 6 June 2008).

2. Lidz C, Roth $L$. The signed form - informed consent. In Boruch R, Cecil J (eds) Solutions to ethical and legal problems in social research. pp 145-157. New York and London: Academic Press, 1983.

3. Fullbrook S. Consent and capacity: principles of the Mental Capacity Act 2005. Br J Nurs 2007; 16: 412-413.

4. The Mental Capacity Act 2005. London: The Stationery Office, 2005. http://www.opsi.gov.uk/ acts/acts2005/ukpga_20050009_en_1 (accessed 6 June 2008)

5. Griffith R. Making decisions for incapable adults: the Scottish law. Br J Community Nurs 2006: 11: 308-313.

6. Davies D. Mental Capacity Act - implications for older people. British Society of Gerodontology Winter Scientific Meeting 2007: 'It's all in the mind'. Chartered Accountants Hall, London, 2007.

7. Emmett C. The Mental Capacity Act 2005 and its impact on dental practice. Br Dent J 2007; 203: 515-521.

8. Davies D. Mental Capacity Act - implications for younger people. British Society of Disability and Oral Health Winter Scientific Meeting 2007: 'Mental health issues and oral health'. Chartered Accountants Hall, London, 2007.

9. Dimond B. Mental capacity and decision making: defining capacity. Br J Nurs 2007; 16: 1138-1139.

10. British Society for Disability and Oral Health. Oral health care for people with mental health problems. Guidelines and recommendations. BSDH 2000. http://www.bsdh.org.uk/guidelines/mental. pdf (accessed 6 June 2008).

11. Johnston C, Liddle J. The Mental Capacity Act 2005: a new framework for healthcare decision making. J Med Ethics 2005; 33: 94-97.

12. Cardiff and Vale Mental Capacity Act Partnership. Mental capacity act network website. www. mentalcapacityact.wales.nhs.uk (accessed 6 June 2008).

13. Kirsch I, Jungeblut A, Jenkins I et al. A first look at the findings of the national adult literacy survey. National Centre for Education Statistics, US Department of Education, 1999.

14. Kempner N. Health literacy in a changing world The Patient's Network 2003; issue 18: 4-8. www.patientsorganizations.org/showarticle. $\mathrm{pl} ? \mathrm{id}=70 ; n=339$

15. French S. On equal terms: working with disabled people. pp 85-161. Oxford: Butterworth-Heinemann, 1994

16. Williams M, Baker D, Honig E, Lee T, Nowlan A. Inadequate literacy is a barrier to asthma knowledge and self-care. Chest 1998; 114: 1008-1015.

17. Baker D, Parker R, Williams M, Clark W. Health literacy and the risk of hospital admission. J Gen Intern Med 1998; 13: 791-798.

18. Hoffman T, McKenna K. Analysis of stroke patients and carers' reading ability and the content and design of written materials: recommendations for improving written stroke information. Patient Educ Couns 2006; 60: 286-293.

19. Pothier D. Many patients do not understand consent forms. BMJ 2005; 330: 1151.

20. Dingwall R. Incomprehensible consent forms: plain English is important. BMJ 2005; 330: 1450.

21. Modood T, Berthoud R, Lakey R. Diversity and disadvantage in Britain. London: Policy Studies Institute, 1997. PSI report no. 843.

22. Dustman C, Fabbri F. Language proficiency and labour market performance of immigrants in the UK. Econ J 2003; 113: 695-717.

23. Doshi M. Oral health of Bangladeshi young adults with a learning disability. London: Kings College London, 2007. MSc dissertation.

24. Gibb F. Dyslexic police inspector wins ruling he is disabled. The Times (London) 2007 July 25. http://business.timesonline.co.uk/tol/business/ law/article2134532.ece

25. Dyslexia Action website. 2008. www.dyslexiaaction.org.uk 
26. British Dyslexia Association website. 2008. www.bdadyslexia.org.uk

27. Dyslexia Association of Ireland. Dyslexia explained webpage. www.dyslexia.ie/dysexp.htm (accessed 6 June 2008)

28. The Dyslexia Institute. The incidence of hidden disabilities in the prison population: Yorkshire and Humberside research. Egham: The Dyslexia Institute, 2005. www.dyslexia-inst.org.uk/pdffiles/Hidden\%20Disabilities\%20Prison.pdf

29. Shirawi L, McDonald F, Newton J. Dyslexia and errors of left-right discrimination in undergraduate dental and postgraduate orthodontic students. J Disabil Oral Health 2007; 8: 23-27.

30. Mathes P, Denton C. The prevention and identification of reading disability. Semin Pediatr Neurol 2002; 9: 185-191.

31. Illingworth K. The effects of dyslexia on the work of nurses and healthcare assistants. Nurs Stand 2005; 19(38): 41-48.

32. The Royal National Institute of Blind People website. 2008. www.rnib.org.uk

33. Mencap website. 2008. www.mencap.org.uk

34. Fiske J, Dickinson C, Boyle C, Rafique S, Burke M. Managing the patient with a learning disability. In Special care dentistry. pp 43-54. London: Quintessence Publishing, 2007.

35. Northfield J. BILD factsheet - what is a learning disability? Kidderminster: British Institute of Learning Disabilities, 2004. http://www.bild.org. uk/pdfs/05faqs/ld.pdf (accessed 6 June 2008).

36. Department of Health. Valuing people: a new strategy for learning disability for the 21st century. London: The Stationery Office, 2001. http://www. archive.official-documents.co.uk/document/ cm50/5086/5086.pdf

37. Department of Health. Making change happen: the government's first annual report on learning disability 2003. London: The Stationery Office, 2003. http://www.dh.gov.uk/en/Publicationsandstatistics/Publications/PublicationsPolicyAndGuidance/ DH_4009998

38. Department of Health. The government's annual report on learning disability 2005. Valuing people: making things better. London: The Stationery Office, 2005. http://www.dh.gov.uk/en/Publicationsandstatistics/Publications/PublicationsPolicyAndGuidance/DH_4123868

39. Department of Health. Good practice in learning disability nursing. London: Department of Health 2007. http://www.dh.gov.uk/en/Publicationsandstatistics/Publications/PublicationsPolicyAndGuidance/DH_081328

40. British Institute of Learning Disability. BILD factsheet - communication. http://www.bild org. uk/pdfs/05faqs/communication.pdf (accessed 6 June 2008)

41. Bowman R. 'Talk-Talk' - a personal view. British Society for Disability and Oral Health Spring Scientific Meeting 2007. Newcastle-Upon-Tyne, 2007.

42. Mencap. Make it clear. A guide to making information easy to read and understand. London: Mencap 2006. Available from http://www.mencap.org.uk/ document.asp? pageType $=112$ \&torigin $=$ pageType

43. Makaton website. 2008. www.makaton.org

44. Homefirst Community Trust. Going to the dentist. Ballymena: Homefirst Community Trust. Available from makaton.org online shop.

45. The Makaton Charity webpage. http://www.makaton.org/about/mvdp.htm (accessed 6 June 2008).

46. The Signalong Group website. www.signalong.org uk (accessed 6 June 2008).

47. Widgit Software website. www.widgit.com (accessed 6 June 2008).
48. Talking Mats website. www.talkingmats.com (accessed 6 June 2008).

49. Murphy J. Talking mats. British Society for Disability and Oral Health Spring Scientific Meeting, 2007. Newcastle Upon Tyne, 2007.

50. Powell S, Northfield J. BILD factsheet on physical interventions. Kidderminster: British Institute for Learning Disabilities, 2002. http://www.bild.org. uk/pdfs/05faqs/pi.pdf (accessed 6 June 2008).

51. Harris P. The nature and extent of aggressive behaviour amongst people with learning difficulties (mental handicap) in a single health district. $J$ Intellect Disabil Res 1993; 37: 221-242.

52. Nunn J, Greening S, Wilson K, Gordon K, Hylton $B$, Griffiths J. Principles on intervention for people unable to comply with routine dental care. British Society for Disability and Oral Health, 2004. www.bsdh.org.uk/guidelines/PIDocument.pdf

53. Harris J, Cornick M, Jefferson A, Mills R. Physical interventions: a policy framework. Kidderminster: BILD Publications, 2006

54. Department of Health. A safer place: combating violence against social care staff - report of the National Task Force and National Action Plan. London: The Stationery Office, 2001.

55. British Institute of Learning Disabilities. BILD Code of practice for trainers in the use of physical interventions: learning disability, autism and pupils with special educational needs. Kidderminster: BILD Publications, 2001.

56. Down's Syndrome Association. Atlanto-axial instability among people with Down's syndrome. Notes for parents and carers. Down's Syndrome Association Medical Series part 3. Teddington: Down's Syndrome Association, 2001. www.dsmig.org.uk/library/articles/ dsa-medical-series-3.pdf 